\title{
Teachers' Subjective Happiness: Testing the Importance of Emotional Intelligence Facets Beyond Perceived Stress
}

\author{
Sergio Mérida-López (D)', Cirenia Quintana-Orts $\mathbb{D}^{2}$, Lourdes Rey $\mathbb{D}^{3}$, Natalio Extremera $\mathbb{D}^{1}$ \\ 'Department of Social Psychology, Social Work, Social Anthropology and East Asian Studies at the University of Malaga, Málaga, Spain; ${ }^{2}$ Department of \\ Developmental and Educational Psychology at the University of Seville, Seville, Spain; ${ }^{3}$ Department of Personality, Evaluation and Psychological \\ Treatment at the University of Malaga, Málaga, Spain \\ Correspondence: Sergio Mérida-López, Department of Social Psychology, Social Work, Social Anthropology and East Asian Studies at the University \\ of Malaga, Málaga, Spain, Tel +34 952137570, Email sergioml@uma.es
}

\begin{abstract}
Purpose: Emotional intelligence (EI) is typically linked to higher subjective happiness scores in human service professionals. It is unknown which EI facets are more predictive in explaining subjective happiness beyond that accounted for by other key predictors such as perceived stress. This study investigated which EI facets were the most predictive in explaining subjective happiness above perceived stress in a relatively large sample of Spanish teachers.

Methods: The sample was composed of 1323 Spanish teaching professionals ( 821 females and 529 secondary school teachers) from different educational centers located in Southern Spain. A student-recruited sampling technique was used, and the surveys included the Wong and Law Emotional Intelligence Scale, the Subjective Happiness Scale, and the Perceived Stress Scale. Predictive and incremental validity was assessed with SPSS, and hierarchical regression analysis was used to predict subjective happiness from EI facets beyond that accounted for by perceived stress.

Results: The results showed that all four EI facets correlated significantly with each other. Also, they all were positively and significantly associated with subjective happiness, whereas perceived stress was negatively associated with happiness scores. Moreover, self-emotion appraisal, use of emotions and regulation of emotions accounted for a significant amount of variance in the prediction of satisfaction with life beyond the effects of sociodemographic variables and perceived stress.

Conclusion: This study extends the specific contribution of EI facets in predicting subjective happiness, rather than EI as a unified construct, in a relatively large sample of Spanish teachers. Self-focused dimensions involving appraisal, use and regulation of emotions appeared to be the most important predictors of happiness beyond stress experienced by teachers. Improved knowledge of the link between specific dimensions of EI and global subjective happiness might improve training in a well-being prevention program for professional development.
\end{abstract}

Keywords: emotional intelligence facets, perceived stress, happiness, teachers

\section{Introduction}

Most teaching professionals believe that happiness is the basis of a meaningful and fulfilling occupational life. ${ }^{1}$ Happiness is commonly referred to as subjective well-being in the field of positive psychology, ${ }^{2}$ being key to retaining new teachers and developing positive job attitudes. ${ }^{3}$ Theoretically, happiness is defined as a more enduring and chronic state than momentary or daily moods, but it is somewhat malleable over time and thus amenable to meaningful pursuit. ${ }^{4}$

For teachers, happiness is a major quality-of-life index because most of the time they are in direct contact with students and parents whose daily interactions require them to be dedicated, positive and energetic. Also, teachers' subjective happiness levels are important because they affect their disposition to proactively teach and interact with students, which may prevent teacher burnout. ${ }^{5}$ Thus, teachers are one of the professionals at highest risk of experiencing stressful situations compared with other human services professions, ${ }^{6,7}$ having to deal with students' 
misbehaviors and discipline problems, heavy workload and time pressure, conflicting staff relationships in school management, and pressure and criticism from parents. All these organizational factors might have a daily impact on teachers' emotional well-being and on their ability to teach effectively and provide positive support to their students. ${ }^{6}$

Because the educational system is one of the most important service providers for our children in current society, improvement of well-being among teaching personnel is a main goal in ensuring healthy teaching staff and providing a supportive school climate that warrants positive and effective learning among their students. ${ }^{89}$ Consistently, a positive psychology approach has been used to examine what individual factors predispose workers to well-being in addition to other organizational factors. ${ }^{10,11}$ For example, some key factors that have an impact on teachers' well-being indicators, such as happiness, include individual resources, positive job attitudes and personal and work-related dynamics. ${ }^{12}$ One such individual resource that may facilitate the coping process and ultimately increase subjective happiness is emotional intelligence (EI). ${ }^{13,14}$

Following the ability model of EI, this dimension is considered to be a psychological construct comprised of interrelated abilities facilitating effective processing of affective information. ${ }^{15}$ Findings from previous meta-analytic reviews have documented that $\mathrm{EI}$ is an important psychological factor in mental and physical health criteria. ${ }^{16,17}$ Also, these emotional abilities are considered to play a key role in promoting positive emotions and might even help to increase people's global well-being and subjective happiness. ${ }^{18}$ According to the literature, EI might exert a positive effect on well-being by reducing the harmful effects of teaching stress provoked by difficult situations in the classroom as well as allowing teachers to engage in more active coping. ${ }^{13,19}$ In this regard, there are studies reporting positive associations between EI and happiness both in occupational ${ }^{20}$ and teacher samples. ${ }^{21}$

Despite recent studies linking EI with subjective well-being indicators, including happiness, a primary limitation of existing findings relates to a lack of facet-level specificity. According to the ability model, EI is a construct comprised of EI facets hierarchically organized from the more basic processes at the lower levels (ie, perceiving emotions) to the more advanced processes at the higher levels (ie, regulating emotions). Indeed, among the most representative feature of the ability model is that the EI construct represents a more specific set of emotional-related skills that can be trained. ${ }^{22}$ Among the few exceptions of studies addressing a facet-level approach when testing the relationship between EI and happiness, there are works with samples of unemployed adults ${ }^{23}$ and with occupational samples. ${ }^{20}$ However, there is no available data indicating on whether EI facets relate to teachers' happiness.

Examining specific EI facets that explain teachers' happiness will help researchers to determine which dimensions are key to be included in further intervention programs with teachers. It is argued that EI facets may act as a teacher's personal resource that facilitates experiences of happiness. ${ }^{13}$ Those teachers who are able to perceive, understand and regulate their emotions might react to stressful situations in the classroom by using more positive resolution strategies. Thus, these EI facets may reduce more effectively the negative effects of stress, which, in turn, might result in higher levels of happiness.

Research literature on general stress has widely shown the role of perceived stress as a contributor to some aspects of emotional maladjustment. ${ }^{24,25}$ Therefore, when stress is not handled appropriately it might impact on the development of negative emotional responses, leading to unhappiness. ${ }^{26,27}$ Given the robust negative link between stress and happiness, predictive studies should examine whether specific EI facets accounted for incremental variance over that accounted for by other well-established constructs, such as teachers' perceived stress. Nevertheless, although previous studies have reported on specific associations among EI facets and well-being indicators in applied contexts, ${ }^{20,23}$ no prior research has examined these associations in teacher samples or controlled for relevant predictors of happiness, such as perceived stress. Such facet-level evidence would be beneficial to design future positive psychology programs targeting the enhancement of happiness among teaching professionals.

Taking into account the above considerations, the current study therefore extends the prior research on teachers' EI and subjective happiness by representing an exploratory investigation into facet-level EI, analyzing how specific facets of EI predict subjective happiness among teachers above and beyond perceived stress levels. We expected EI facets to be positively associated with happiness and perceived stress to be negatively linked to teachers' happiness. Thus, consistent with past meta-analytic evidence on global EI and well-being, we predicted that teachers' EI facets would be significantly and positively related to subjective happiness. ${ }^{18}$ However, no specific predictions regarding the relative contribution of EI facets to happiness when controlling for perceived stress were made because the current evidence in this line is limited. 


\section{Methods}

\section{Research Design and Procedure}

A cross-sectional survey was conducted between October 2017 and February 2018. The study was conducted with the ethical approval of the hosting University (No. 66-2018-H). Data collection was based on a student-recruited sampling method. ${ }^{28}$ According to this non-probability and convenience sampling method, participants were recruited with the help of psychology students who contacted different educational centers located in southern Spain. Undergraduate students were instructed on how to administer the surveys correctly and they asked teaching professionals whether they would be willing to participate in a study on emotions and well-being. Questionnaires were completed either at home or in small groups under the supervision of a research assistant. Completing the surveys, including the study variables, lasted 15 minutes on average. The questionnaires were in a paper-and-pencil format with written instructions. Anonymity was assured as no personal or identifying information was asked. Participants were fully informed about the purpose of the study as well as the individual, confidential and voluntary nature of the questionnaire. The surveys included informed consent documents with a brief description of the study aim.

\section{Participants}

Approximately 2400 questionnaires were distributed in centers of childhood, primary, secondary and post-secondary education. Common inclusion criteria were being working as a teaching professional at the time of the data collection as well as being willing to participate in the research. A total of 1359 surveys were collected, yielding a response rate of $56.63 \%$. At the stage of statistical processing, it was found that 36 questionnaires were incomplete and therefore were removed. Thus, the final study sample comprised 1323 teaching professionals (for a description of the sample, see the Results section).

\section{Measures}

\section{Emotional Intelligence}

The Wong and Law Emotional Intelligence Scale (WLEIS) was included in the survey to assess EI dimensions. ${ }^{29}$ The instrument contains 16 items covering four dimensions (with four items each), in line with Mayer and Salovey's EI model: $^{30}$ self-emotion appraisal, other-emotion appraisal, use of emotion and regulation of emotion. Participants are asked to give a response using a seven-point Likert-type scale from 1 ("totally disagree") to 7 ("totally agree"). Some example items are "I always encourage myself to try my best" (use of emotion) and "I am sensitive to the feelings and emotions of others" (other-emotion appraisal). The Spanish version, which has yielded adequate validity and reliability, was used in this study. ${ }^{31}$ In the present study, internal consistency was good for all subscales, as indicated by Cronbach's $\alpha$ (and McDonald's $\Omega$ ) estimates: $0.82(0.82)$ for self-emotion appraisal, $0.83(0.84)$ for other-emotion appraisal, 0.79 $(0.79)$ for use of emotion and $0.85(0.85)$ for regulation of emotion.

\section{Perceived Stress}

The short version of the Perceived Stress Scale (PSS-4) was used to assess the frequency of stress. ${ }^{32}$ This brief scale includes four items asking participants to rate the frequency during the last month with which they have experienced situations they consider as stressful. Respondents are given a five-point Likert scale ranging from 0 ("never") to 4 ("very often"). One example item is "In the last month, how often have you been upset because of something that happened unexpectedly?". A well validated Spanish version was used in this study. ${ }^{33}$ In this work, internal consistency was good: Cronbach's $\alpha=0.72$ and McDonald's $\Omega=0.72$.

\section{Happiness}

The Subjective Happiness Scale (SHS) was used to assess happiness. ${ }^{34}$ This scale contains four items assessed on a seven-point Likert scale ranging from 1 ("Not a very happy person") to 7 ("A very happy person"). While two items ask respondents to describe themselves using both absolute ratings and ratings relative to peers, the remaining two items offer brief descriptions of happy and unhappy individuals (eg, "In general I consider myself": 1 = not a very happy person; $7=$ a very happy person). In this study, the Spanish version was used, which has shown good validity and reliability. ${ }^{35}$ Internal consistency estimates were good in this work: Cronbach's $\alpha=0.79$ and McDonald's $\Omega=0.79$. 


\section{Statistical Analyses}

Descriptive analyses (ie, means and standard deviations) and bivariate correlations were conducted using SPSS 24.0. Then, to test whether specific EI facets would account for variance in subjective happiness after controlling for the effects of sociodemographic variables (ie, age, gender, teaching level, teaching experience and contractual status) and perceived stress, multiple linear regression analysis was used and variables were added in three steps. In the first step, age, gender, teaching level, teaching experience and contractual status were entered as covariates. As prior studies have found that several sociodemographic and work-related variables potentially explain differences in subjective well-being, ${ }^{21,23,35}$ these variables were included in regression analyses to avoid confounding effects. In the second step, the score in perceived stress was entered, and in the third step, scores in the four EI dimensions were entered.

Preliminary analyses were conducted prior to the main analyses to ensure there was no important violation of assumptions of normality, independence, multicollinearity and homoscedasticity. The Kolmogorov-Smirnov test was used for normality assessment. Results showed that subjective happiness was not normally distributed. However, the skewness (-0.74) and kurtosis (0.71) values fell below the threshold of 3.0 and 8.0, respectively. ${ }^{36}$ Regarding independence, the Durbin-Watson value was 1.93, which confirmed this assumption. With regard to the assumption of multicollinearity, all correlations were less than the threshold of $0.70,{ }^{37}$ showing the likelihood of multicollinearity to be low. Moreover, the variance inflation factor (VIF) values ranged between 1.07 and 3.27, which added support to this assumption. Finally, the assumption of homoscedasticity was supported by the residual scatterplots.

\section{Results}

\section{Descriptive Results}

Table 1 summarizes the main characteristics of the study sample. As shown, most of the participants were: female (62.1\%), secondary school teachers $(40 \%)$, marital status reported as married $(60.8 \%)$ and with an indefinite contract at state-run institutions $(62.4 \%)$. Mean age for the total sample was 44.46 years $(S D=9.24$; range $=22-68)$. For each teaching level, a similar age range was found: range = 22-66 (childhood); 23-63 (primary); 24-68 (secondary); 31-68 (post-secondary). Teaching experience was 17 years on average $(M=16.55 ; S D=9.87)$.

Table 2 shows the Pearson bivariate correlations among the study variables. As shown, all the EI dimensions were negatively associated with perceived stress and positively related to subjective happiness. Moreover, perceived stress was negatively linked with subjective happiness.

\section{Predictive Validity of El Facets on Teachers' Happiness Beyond Perceived Stress}

Results regarding the regression analyses are shown in Table 3. Some of the sociodemographic variables (ie, gender, age and contractual status) were predictive of subjective happiness. These variables accounted for $2.4 \%$ of the variance $\left(\Delta R^{2}\right.$ $=0.024 ; p<0.001)$ in happiness $[F(6,1316)=5.36 ; p<0.001]$. Moreover, perceived stress was predictive of lower happiness after controlling for the covariates $(B=-0.59, p<0.001)$ and predicted an additional $29.8 \%$ of the variance $\left(\Delta R^{2}=0.298 ; p<0.001\right)$ in this variable $[F(7,1315)=89.25 ; p<0.001]$. Finally, several EI facets were found to be predictive of happiness after controlling for the variance due to the covariates and perceived stress, accounting for an additional $9.9 \%$ of the variance $\left(\Delta R^{2}=0.099 ; p<0.001\right)$ in subjective happiness $[F(11,1311)=86.68 ; p<0.001]$. In particular, self-emotion appraisal $(B=0.10, p<0.01)$, use of emotion $(B=0.26, p<0.001)$ and regulation of emotion $(B=0.09, p<0.01)$ emerged as significant predictors of subjective happiness. However, other-emotion appraisal was not found to be a significant predictor $(B=-0.04, p=0.17)$. The final model accounted for $42.1 \%$ of the variance $\left(R^{2}=0.42\right.$; $p<0.001)$ in happiness.

\section{Discussion}

This study sought to test the predictive validity of EI facets on happiness beyond the effects of perceived stress in a sample of teaching professionals. Current literature offers a growing body of research relating teachers' overall EI with a variety of personal and work-related well-being indicators. ${ }^{13,19}$ However, this work adds to an existing literature gap and goes beyond earlier studies by considering facets of EI scores in the explanation of a salient well-being indicator 
Table I Overview of the Main Characteristics of the Study Participants

\begin{tabular}{|l|c|}
\hline Sociodemographic Variable & $\mathbf{n}(\%)$ \\
\hline Gender & \\
Female & $821(62.1 \%)$ \\
Male & $502(37.9 \%)$ \\
Age group & \\
$22-34$ & $204(15.4 \%)$ \\
$35-49$ & $674(50.9 \%)$ \\
$50-68$ & $445(33.6 \%)$ \\
Teaching level & \\
Childhood education & $155(11.7 \%)$ \\
Primary education & $406(30.7 \%)$ \\
Secondary education & $529(40 \%)$ \\
Post-secondary education & $68(5.1 \%)$ \\
Non-specified & $165(12.5 \%)$ \\
Work experience & \\
I-I0 years & $442(33.4 \%)$ \\
II-20 years & $426(32.2 \%)$ \\
$>$ 2I years & $455(34.4 \%)$ \\
Marital status & \\
Single & $361(27.3 \%)$ \\
Married & $805(60.8 \%)$ \\
Divorced/Separated & $88(6.7 \%)$ \\
Widow/widower & $20(1.5 \%)$ \\
Coupled & $17(1.3 \%)$ \\
Non-specified & $32(2.4 \%)$ \\
Contractual status & \\
Indefinite contract at state-run institutions & $825(62.4 \%)$ \\
Temporary contract & $135(10.2 \%)$ \\
Others/non-specified & $363(27.5 \%)$ \\
\hline & \\
\hline
\end{tabular}

Table 2 Descriptive Statistics and Bivariate Correlations

\begin{tabular}{|c|c|c|c|c|c|c|}
\hline Variables & $\mathbf{I}$ & 2 & 3 & 4 & 5 & 6 \\
\hline I. Self-emotion appraisal & I & & & & & \\
\hline 2. Other-emotion appraisal & 0.55 & I & & & & \\
\hline 3. Use of emotion & 0.59 & 0.50 & I & & & \\
\hline 4. Regulation of emotion & 0.62 & 0.39 & 0.53 & I & & \\
\hline 5. Perceived stress & -0.41 & -0.19 & -0.34 & -0.37 & I & \\
\hline 6. Subjective happiness & 0.44 & 0.26 & 0.47 & 0.41 & -0.55 & I \\
\hline Mean & 5.63 & 5.50 & 5.58 & 5.26 & 1.17 & 5.40 \\
\hline SD & 0.88 & 0.92 & 0.89 & 0.96 & 0.64 & 0.95 \\
\hline
\end{tabular}

Notes: $\mathrm{N}=$ 1323. All correlations coefficients were significant at $p<0.001$ level.

such as happiness. Results on the negative effect between perceived stress and teachers' happiness were consistent with prior studies showing that workers experiencing stress find it harder to experience positive emotions, which in turn affects general well-being. ${ }^{27,38}$ Moreover, results regarding the positive association between EI facets and teachers' happiness were in line with prior research showing that EI facets involving perception, understanding or regulation of emotions may be relevant for achieving greater levels of subjective well-being. ${ }^{23,39}$

Given the influence of multiple factors contributing to happiness, ${ }^{11}$ it was expected that teachers' EI facets may still continue to be involved in predicting their levels of happiness even after controlling for the effects of perceived stress. 
Table 3 Main Results for the Regression Analysis with Subjective Happiness as Dependent Variable

\begin{tabular}{|c|c|c|c|c|c|}
\hline & B & SE & $\mathbf{t}$ & $p$ & $\mathrm{BCa} 95 \% \mathrm{Cl}$ for $\mathrm{B}$ \\
\hline Gender & 0.09 & 0.04 & 2.04 & $*$ & [0.003 to 0.173$]$ \\
\hline Age & -0.02 & 0.00 & -4.18 & $* * *$ & {$[-0.024$ to -0.009$]$} \\
\hline Marital status & 0.01 & 0.02 & 0.64 & 0.522 & {$[-0.029$ to 0.057$]$} \\
\hline Teaching level & 0.04 & 0.02 & 1.93 & 0.054 & {$[-0.001$ to 0.078$]$} \\
\hline Teaching experience & 0.00 & 0.00 & 1.61 & 0.109 & {$[0.000$ to 0.001$]$} \\
\hline Contractual status & -0.04 & 0.01 & -3.15 & $* *$ & {$[-0.069$ to -0.016$]$} \\
\hline Perceived stress & -0.59 & 0.04 & $-|6.9|$ & $* * *$ & {$[-0.659$ to -0.522$]$} \\
\hline Self-emotion appraisal & 0.10 & 0.03 & 2.95 & $* *$ & {$[0.033$ to 0.166$]$} \\
\hline Other-emotion appraisal & -0.04 & 0.03 & -1.36 & 0.174 & {$[-0.092$ to 0.017$]$} \\
\hline Use of emotion & 0.26 & 0.03 & 8.67 & $* * *$ & {$[0.201$ to 0.318$]$} \\
\hline Regulation of emotion & 0.09 & 0.03 & 3.17 & $* *$ & [0.034 to 0.143$]$ \\
\hline
\end{tabular}

Notes: The beta reported in the table is the unstandardized regression coefficient for the final equation. ${ }^{*} p<0.05, *^{*} p<0.0 \mathrm{I}, *_{*} * p<0.00 \mathrm{I}$.

Abbreviations: $B$, unstandardized beta; $\mathrm{BCa} 95 \% \mathrm{Cl}$ for B, confidence interval with lower and upper limits for beta coefficients; SE, standard error.

Findings showed that teaching professionals perceiving themselves as more skilled at perceiving, using and regulating their own emotions, reported greater scores in happiness even after accounting for the effects of sociodemographic factors and perceived stress. First, results on the predictive validity of self-emotion appraisal on teachers' happiness relate to the benefits of this basic EI dimension, allowing individuals to engage in more adaptive emotion regulation strategies. ${ }^{40}$ These results are in line with the so-called cascading model of EI, indicating that emotionally savvy individuals are more capable of identifying how they feel and are more likely to implement effective strategies to direct their emotions to desirable states in order to achieve better functioning in demanding contexts. ${ }^{40}$ Accordingly, it is plausible that teaching professionals, being more capable of perceiving their emotions when facing an event, may count on a key resource for eventually implementing useful emotion regulation strategies, thereby experiencing higher well-being. ${ }^{41}$

Second, the fact that use of emotion was predictive of happiness after accounting for perceived stress parallels previous findings underlining this EI facet as an antecedent of well-being. ${ }^{23}$ This dimension includes skills allowing individuals to take into account the benefits of emotions to guide cognitive processes and to direct emotions to constructive activities. ${ }^{15}$ Accordingly, teachers with highly developed abilities to use their emotions for constructive and self-motivating activities may find it easier to encourage themselves to maintain their well-being. Therefore, they may score higher in happiness than their counterparts with lower skills for using their emotions. Third, the finding that regulation of emotion was positively associated with teachers' happiness accords with existing studies reporting the positive effects of this EI facet among teaching professionals. ${ }^{7}$ This EI facet may allow individuals to select and implement adaptive emotion regulation strategies leading to enhanced well-being and improved performance. ${ }^{40,42}$ In the teaching context, emotion regulation has been proposed as a relevant EI dimension in helping teachers to experience more positive emotions and engage in more adaptive strategies to deal with situations leading to unpleasant emotions. ${ }^{13,19}$

In contrast to the remaining EI facets, other-emotion appraisal did not show predictive validity on happiness after controlling for the effects of perceived stress. This non-significant finding may be explained by attending to the nature of this EI dimension. From the ability EI model, appraisal of others' emotions relates to awareness of, and sensitivity to, the emotions of other individuals. ${ }^{15}$ Teachers scoring higher in other-emotion appraisal may find it easier to garner relevant clues and information on the goals or attitudes of their colleagues or students. Nonetheless, this competence may not be as relevant as a dimension associated with individual well-being, with the focus on one's own emotions (eg, self-emotion appraisal or use of emotion). In fact, this finding accords with prior research showing a stronger relationship between teachers' self-focused appraisal and burnout in comparison with other-focused emotion appraisal. ${ }^{41}$ Similarly, these 
results align with previous works showing self-focused EI facets (but not other-focused dimensions) as predictors of indicators of health ${ }^{43}$ and well-being. ${ }^{44}$

\section{Theoretical and Practical Implications}

With regard to the theoretical contributions of this study, this work features among the first attempts to examine the predictive validity of EI facets in teachers' well-being. By doing so, this study provided more detailed knowledge on the associations among teachers' EI dimensions, perceived stress and happiness than is available in the existing literature. Considering that self-focused EI dimensions emerged as relevant predictors of teachers' happiness, this study may serve as a starting point to further delineate the mechanisms underlying the effects of self-focused EI dimensions in relation to teachers' well-being. Current and previous results reporting that self-focused EI facets may precede the individuals' capacity to adequately manage their own emotions encourage future works to determine which strategies help teachers to maintain optimal levels of well-being in demanding contexts. ${ }^{13,40}$ Further, it could be tested whether other-focused EI facets may lead to more positive relationships with students so that teachers may experience greater well-being. ${ }^{41}$ In summary, this study points to the potential benefits of exploring the effects of EI dimensions in relation to individual and school-level well-being.

Regarding the practical implications of this study, a promising direction for positive psychology programs with teaching professionals may be not only focusing on stress management interventions but also including EI development as a complementary strategy for the promotion of subjective well-being in this context. ${ }^{22,45}$ Providing teachers with strategies to prevent future events from generating dissatisfaction and ill-being, it may be helpful to design EI training programs in which key EI facets are taught. Considering the current findings, such an avenue may consider self-focused EI dimensions as strategies that facilitate subjective well-being. One beneficial way to increase teachers' happiness would be to help them to incorporate new habits so that they discuss stressful events at work (ie, self-emotion appraisal) and how to solve them (ie, self-emotion regulation). Moreover, they could be taught how to make the most of their positive emotions at work (ie, use of emotion). This approach may make them perceive the school environment as less threatening and contribute to facilitate their levels of happiness regarding personal and work-related domains. ${ }^{11,46}$ These activities may allow teachers to anticipate future events in which they may feel overwhelmed and thus contribute to more positive states, including happiness and commitment. ${ }^{10}$ Notwithstanding strategies targeting teacher stress, the results from this study support the implementation of activities with a facet-level approach to contribute to teacher well-being through EI development.

\section{Limitations and Future Research}

There are several limitations that should be considered. First, the cross-sectional nature of the design precludes any conclusion regarding the causal relationship among variables. Despite the proposed associations being rooted in theory, future studies adopting longitudinal designs would beneficially add to the existing evidence. For instance, it could be tested whether teachers scoring higher in EI facets do show differences in their perceptions of stress and happiness across time and situations at work. Moreover, studies may focus not only on the effects of EI facets in happiness but in other potential mediating and moderating factors in in this relationship. ${ }^{47}$ Accordingly, future works in this line may follow the current results to test the cascading model of EI, with the aim of confirming whether self-focused emotion appraisal may lead to increased teachers' happiness through self-focused emotion regulation and reduced stress. ${ }^{40}$ Second, despite the results being based on a relatively large sample of teaching professionals, the incidental sampling method used with a sample of Spanish teachers makes it difficult to generalize the current findings. Thus, additional studies with random sampling methods and more heterogeneous samples would contribute to the existing knowledge on the role of EI facets in predicting teachers' well-being. Finally, it should be noted that self-report measures were used for the study variables. Despite the insightful results of this study, further works that include objective as well as self-report measures are needed. In this regard, qualitative and mixed-method approaches would help to delve into the mechanisms linking emotional management with relevant outcomes such as teacher attrition. ${ }^{46}$ 


\section{Conclusions}

In summary, the findings from this research may contribute to better understanding of which facets of EI may be most relevant in explaining teachers' happiness indicating that their predictive power is not simply attributable to overlap with measures of stress-related constructs. These results may be informative to practitioners and policymakers aiming at designing efficient efforts for promoting well-being in this work context. Notwithstanding the relevance of interventions targeting the reduction of stress and the promotion of happiness at work, results from this study underscore the need for paying attention to those self-focused emotional resources that may contribute to the major goal of sustaining happier and healthier educational organizations.

\section{Abbreviations}

EI, emotional intelligence; WLEIS, Wong and Law Emotional Intelligence Scale; PSS, Perceived Stress Scale; SHS, Subjective Happiness Scale.

\section{Data Sharing Statement}

The datasets analyzed in the current study are not publicly available because the dataset has been generated regarding a funded Research Project by Junta de Andalucia/FEDER funds (UMA18-FEDERJA-147). Reasonable requests to access the datasets should be directed to NE.

\section{Ethics Approval and Informed Consent}

All procedures were approved by the ethics committee of University of Malaga (CEUMA; approval number 66/2018-H) and followed the tenets of the Declaration of Helsinki. All participants provided informed consent to participate.

\section{Acknowledgments}

The authors acknowledge the teachers who took part in this study for their sincere responses to the survey.

\section{Author Contributions}

All authors made a significant contribution to the work reported, whether that is in the conception, study design, execution, acquisition of data, analysis and interpretation, or in all these areas. All authors have drafted, written and substantially and critically revised the article. All authors discussed the results, implications, and literature on previous versions of the manuscript. All authors read and approved the final version of the manuscript for submission and agree to be accountable for all aspects of the work. All authors gave final approval of the version to be published and have agreed on the journal to which the article has been submitted.

\section{Funding}

This research was funded in part by research projects from the University of Málaga and Junta de Andalucía/FEDER (UMA18-FEDERJA-147), funded projects by the Spanish Ministry of Science and Innovation (PID2020-117006RB-I00) and PAIDI Group CTS-1048 (Junta de Andalucía). The first author is supported by the University of Málaga. The second author is supported by a "Juan de la Cierva-Formación" Postdoctoral Research Fellowship from the Spanish Ministry of Science, Innovation and Universities (FJC2019-038942-I/AEI/10.13039/501100011033).

\section{Disclosure}

No potential conflicts of interest for this work were reported by the authors.

\section{References}

1. De Stercke J, Goyette N, Robertson JE. Happiness in the classroom: strategies for teacher retention and development. Prospects. 2015;45 (4):421-427. doi:10.1007/s11125-015-9372-z

2. Pavot W, Diener E. Happiness experienced: the science of subjective well-being. In: The Oxford Handbook of Happiness. Oxford University Press; 2013:134-151. 
3. De Stasio S, Fiorilli C, Benevene P, et al. Subjective happiness and compassion are enough to increase teachers' work engagement? Front Psychol. 2019;10:2262. doi:10.3389/fpsyg.2019.02268

4. Lyubomksky S, Sheldon KM, Schkade D. Pursuing happiness: the architecture of sustainable change. Rev Gen Psychol. 2005;9(2):111-131. doi:10.1037/1089-2680.9.2.111

5. Chan DW. Orientations to happiness and subjective well-being among Chinese prospective and in-service teachers in Hong Kong. Educ Psychol. 2009;29(2):139-151. doi:10.1080/01443410802570907

6. Travers C. Current knowledge on the nature, prevalence, sources and potential impact of teacher stress. In: Educator Stress: An Occupational Health Perspective. Springer International Publishing; 2017:23-54.

7. Iriarte Redín C, Erro-Garcés A. Stress in teaching professionals across Europe. Int J Educ Res. 2020;103:101623. doi:10.1016/j.ijer.2020.101623

8. Soini T, Pyhältö K, Pietarinen J. Pedagogical well-being: reflecting learning and well-being in teachers' work. Teach Teach Theory Pract. 2010;16 (6):735-751. doi:10.1080/13540602.2010.517690

9. UNESCO. Nurturing the social and emotional wellbeing of children and young people during crises. UNESCO COVID-19 education response; 2020. Available from: https://unesdoc.unesco.org/ark:/48223/pf0000373271. Accessed November 17, 2021.

10. Diener E, Thapa S, Tay L. Positive emotions at work. Annu Rev Organ Psychol Organ Behav. 2020;7:451-477. doi:10.1146/annurev-orgpsych012119-044908

11. Fisher CD. Happiness at work. Int J Manag Rev. 2010;12(4):384-412. doi:10.1111/j.1468-2370.2009.00270.x

12. Granziera H, Collie R, Martin A. Understanding teacher wellbeing through job demands-resources theory. In: Cultivating Teacher Resilience. International Approaches, Applications and Impact. Springer; 2021:229-244.

13. Vesely AK, Saklofske DH, Leschied ADW. Teachers- the vital resource: the contribution of emotional intelligence to teacher efficacy and well-being. Can J Sch Psychol. 2013;28(1):71-89. doi:10.1177/0829573512468855

14. Zeidner M, Matthews G, Roberts RD. Emotional intelligence, coping with stress, and adaptation. In: Emotional Intelligence in Everyday Life. Psychology Press; 2006:100-127.

15. Mayer JD, Caruso DR, Salovey P. The ability model of emotional intelligence: principles and updates. Emot Rev. 2016;8(4):290-300. doi:10.1177/ 1754073916639667

16. Martins A, Ramalho N, Morin E. A comprehensive meta-analysis of the relationship between emotional intelligence and health. Pers Individ Dif. 2010;49(6):554-564. doi:10.1016/j.paid.2010.05.029

17. Sarrionandia A, Mikolajczak M. A meta-analysis of the possible behavioural and biological variables linking trait emotional intelligence to health. Health Psychol Rev. 2020;14(2):220-244. doi:10.1080/17437199.2019.1641423

18. Sánchez-álvarez N, Extremera N, Fernández-Berrocal P. The relation between emotional intelligence and subjective well-being: a meta-analytic investigation. J Posit Psychol. 2016;11(3):276-285. doi:10.1080/17439760.2015.1058968

19. Mérida-López S, Extremera N. Emotional intelligence and teacher burnout: a systematic review. Int J Educ Res. 2017;85:121-130. doi:10.1016/j. ijer.2017.07.006

20. Blasco-Belled A, Rogoza R, Torrelles-Nadal C, Alsinet C. Emotional intelligence structure and its relationship with life satisfaction and happiness: new findings from the bifactor model. J Happiness Stud. 2020;21(6):2031-2049. doi:10.1007/s10902-019-00167-x

21. Peláez-Fernández MA, Mérida-López S, Sánchez-álvarez N, Extremera N. Managing teachers' job attitudes: the potential benefits of being a happy and emotional intelligent teacher. Front Psychol. 2021;12:661151. doi:10.3389/fpsyg.2021.661151

22. Hodzic S, Scharfen J, Ripoll P, Holling H, Zenasni F. How efficient are emotional intelligence trainings: a meta-analysis. Emot Rev. 2018;10 (2):138-148. doi:10.1177/1754073917708613

23. Berrios MP, Extremera N, Nieto-Flores MP. Exploring the socio-emotional factors associated with subjective well-being in the unemployed. PeerJ. 2016;4:e2506. doi:10.7717/peerj.2506

24. Cohen S, Janicki-Deverts D, Miller GE. Psychological stress and disease. JAMA. 2007;298(14):1685-1687. doi:10.1001/jama.298.14.1685

25. Cohen S, Kessler R, Underwood Gordon L. Measuring Stress: A Guide for Health and Social Scientists. New York: Oxford University Press; 1995.

26. Matthews G, Zeidner M, Roberts RD. Emotional intelligence, health, and stress. In: The Handbook of Stress and Health: A Guide to Research and Practice. Wiley-Blackwell; 2017:312-326.

27. Schiffrin HH, Nelson SK. Stressed and happy? Investigating the relationship between happiness and perceived stress. J Happiness Stud. 2010;11 (1):33-39. doi:10.1007/s10902-008-9104-7

28. Wheeler AR, Shanine KK, Leon MR, Whitman MV. Student-recruited samples in organizational research: a review, analysis, and guidelines for future research. J Occup Organ Psychol. 2014;87(1):1-26. doi:10.1111/joop.12042

29. Wong C-S, Law KS. The effects of leader and follower emotional intelligence on performance and attitude. Leadersh Q. 2002;13(3):243-274. doi:10.1016/S1048-9843(02)00099-1

30. Mayer JD, Salovey P. What is emotional intelligence? In: Emotional Development and Emotional Intelligence: Implications for Educators. New York: Basic Books; 1997:3-31.

31. Extremera N, Rey L, Sánchez-álvarez N. Validation of the Spanish version of Wong Law Emotional Intelligence Scale (WLEIS-S). Psicothema. 2019;31(1):94-100. doi:10.7334/psicothema2018.147

32. Cohen S, Kamarck T, Mermelstein R. A global measure of perceived stress. J Health Soc Behav. 1983;24(4):385. doi:10.2307/2136404

33. Remor E, Carrobles J. Versión Española de la Escala de Estrés Percibido (PSS-14): estudio psicométrico en una muestra VIH+. Ansiedad y Estrés. 2001;7(2-3):195-201.

34. Lyubomirsky S, Lepper HS. A measure of subjective happiness: preliminary reliability and construct validation. Soc Indic Res. 1999;46:137-155. doi:10.1023/A:1006824100041

35. Extremera N, Fernández-Berrocal P. The subjective happiness scale: translation and preliminary psychometric evaluation of a Spanish version. Soc Indic Res. 2014;119(1):473-481. doi:10.1007/s11205-013-0497-2

36. Kline RB. Principles and Practices of Structural Equation Modeling. Guilford Press; 2010.

37. Tabachnick BG, Fidell LS. Using Multivariate Statistics. Allyn and Bacon; 2001.

38. Schonfeld IS, Bianchi R, Luehring-Jones P. Consequences of job stress for the mental health of teachers. In: Educator Stress: An Occupational Health Perspective. Springer International Publishing; 2017:55-75. 
39. Pena M, Rey L, Extremera N. Life satisfaction and engagement in elementary and primary educators: differences in emotional intelligence and gender. J Psychodidactics. 2012;17(2):341-358. doi:10.1387/Rev.Psicodidact.4496

40. Joseph DL, Newman DA. Emotional intelligence: an integrative meta-analysis and cascading model. J Appl Psychol. 2010;95(1):54-78. doi:10.1037/a0017286

41. Nizielski S, Hallum S, Schütz A, Lopes PN. A note on emotion appraisal and burnout: the mediating role of antecedent-focused coping strategies. J Occup Health Psychol. 2013;18(3):363-369. doi:10.1037/a0033043

42. Côté S. Emotional intelligence in organizations. Annu Rev Organ Psychol Organ Behav. 2014;1:459-488. doi:10.1146/annurev-orgpsych-031413091233

43. Mikolajczak M, Avalosse H, Vancorenland S, et al. A nationally representative study of emotional competence and health. Emotion. 2015;15 (5):653-667. doi:10.1037/emo0000034

44. Mérida-López S, Extremera N, Chambel MJ. Linking self- and other-focused emotion regulation abilities and occupational commitment among pre-service teachers: testing the mediating role of study engagement. Int J Environ Res Public Health. 2021;18(10):5434. doi:10.3390/ ijerph 18105434

45. Rahm T, Heise E. Teaching happiness to teachers - development and evaluation of a training in subjective well-being. Front Psychol. 2019;10:2703. doi:10.3389/fpsyg.2019.02703

46. Wang H, Hall NC. Exploring relations between teacher emotions, coping strategies, and intentions to quit: a longitudinal analysis. J Sch Psychol. 2021;86:64-77. doi:10.1016/j.jsp.2021.03.005

47. Badri SKZ, Kong MY, Yunus WM, Nordin NA, Yap WM. Trait emotional intelligence and happiness of young adults: the mediating role of perfectionism. Int J Environ Res Public Health. 2021;18(20):10800. doi:10.3390/ijerph182010800

\section{Publish your work in this journal}

Psychology Research and Behavior Management is an international, peer-reviewed, open access journal focusing on the science of psychology and its application in behavior management to develop improved outcomes in the clinical, educational, sports and business arenas. Specific topics covered in the journal include: Neuroscience, memory and decision making; Behavior modification and management; Clinical applications; Business and sports performance management; Social and developmental studies; Animal studies. The manuscript management system is completely online and includes a very quick and fair peer-review system, which is all easy to use. Visit http://www.dovepress.com/testimonials.php to read real quotes from published authors.

Submit your manuscript here: https://www.dovepress.com/psychology-research-and-behavior-management-journal 